\title{
The olivo-cerebellar system: a key to understanding the functional significance of intrinsic oscillatory brain properties
}

\section{Rodolfo R. Llinás*}

Department of Physiology and Neuroscience, New York University School of Medicine, New York, NY, USA

\section{Edited by:}

Egidio D'Angelo, University of Pavia, Italy

\section{Reviewed by:}

Egidio D'Angelo, University of Pavia, Italy

Chris I. De Zeeuw, Erasmus MC

Rotterdam and Royal Dutch

Academy of Arts and Sciences,

Netherlands

\section{*Correspondence:}

Rodolfo R. Llinás, Department of Physiology and Neuroscience, New York University School of Medicine, 550 1st Ave., New York, NY 10016, USA

e-mail: rodolfo.llinás@med.nyu.edu
The reflexological view of brain function (Sherrington, 1906) has played a crucial role in defining both the nature of connectivity and the role of the synaptic interactions among neuronal circuits. One implicit assumption of this view, however, has been that CNS function is fundamentally driven by sensory input. This view was questioned as early as the beginning of the last century when a possible role for intrinsic activity in CNS function was proposed by Thomas Graham Brow (Brown, 1911, 1914). However, little progress was made in addressing intrinsic neuronal properties in vertebrates until the discovery of calcium conductances in vertebrate central neurons leading dendritic electroresponsiveness (Llinás and Hess, 1976; Llinás and Sugimori, 1980a,b) and subthreshold neuronal oscillation in mammalian inferior olive (IO) neurons (Llinás and Yarom, 1981a,b). This happened in parallel with a similar set of findings concerning invertebrate neuronal system (Marder and Bucher, 2001). The generalization into a more global view of intrinsic rhythmicity, at forebrain level, occurred initially with the demonstration that the thalamus has similar oscillatory properties (Llinás and Jahnsen, 1982) and the ionic properties responsible for some oscillatory activity were, in fact, similar to those in the IO (Jahnsen and Llinás, 1984; Llinás, 1988). Thus, lending support to the view that not only motricity, but cognitive properties, are organized as coherent oscillatory states (Pare et al., 1992; Singer, 1993; Hardcastle, 1997; Llinás et al., 1998; Varela et al., 2001).

Keywords: intrinsic oscillatory, olivo-cerebellar, electrophysiology, IO neurons, PO neuron oscillation

\section{INTRODUCTION}

The reflexological view of brain function (Sherrington, 1906) has played a crucial role in defining both the nature of connectivity and the role of the synaptic interactions among neuronal circuits. One implicit assumption of this view, however, has been that CNS function is fundamentally driven by sensory input.

This view was questioned as early as the beginning of the last century when Thomas Graham Brown proposed a possible role for intrinsic activity in CNS function (Brown, 1911, 1914). However, little progress was made in addressing intrinsic neuronal properties in vertebrates until the discovery of calcium conductances in vertebrate central neurons leading dendritic electroresponsiveness (Llinás and Hess, 1976; Llinás and Sugimori, 1980a,b) and subthreshold neuronal oscillation in mammalian inferior olive (IO) neurons (Llinás and Yarom, 1981a,b). This happened in parallel with a similar set of findings concerning invertebrate neuronal system (Marder and Bucher, 2001). The generalization into a more global view of intrinsic rhythmicity at forebrain level occurred initially with the demonstration that the thalamus has similar oscillatory properties (Llinás and Jahnsen, 1982) and the ionic properties responsible for some oscillatory activity were, in fact, similar to those in the IO (Jahnsen and Llinás, 1984; Llinás, 1988). Thus, lending support to the view that not only motricity, but also cognitive properties, are organized as coherent oscillatory states (Pare et al., 1992; Singer, 1993; Hardcastle, 1997; Llinás et al., 1998; Varela et al., 2001).

Concerning the functional significance of IO intrinsic properties two main issues should be addressed; (1) the predictive aspects movement intentionality and its translation into motor strategy and tactics and (2) the timing of motor execution. In reviewing the global properties of IO function I will briefly address general anatomy and electrophysiology of IO nucleus and it neurons.

\section{GENERAL IO ANATOMY}

The olivocerebellar system is one of the most conserved in the vertebrate brain, being present in all such forms studied (AriensKappers et al., 1936). It comprises a set of bilaterally symmetrical inferior olivary nuclei (IO) and the overlaying cerebellum. These two structures are mutually linked through axonal pathways within the cerebellar peduncles. Some IO neurons have spherical dendritic trees (Figure 1C). Their axons traverse the midline at the bulbar region (Figure 1A, orange), course up the contralateral cerebellar peduncle, and enter the cerebellar white matter. From there branches establish excitatory synaptic contacts with the cerebellar nuclear neurons (Figure 1A green and purple) while the axons proceed into the cerebellar cortex to establish the most powerful synaptic contact in the brain the so called climbing fiber 

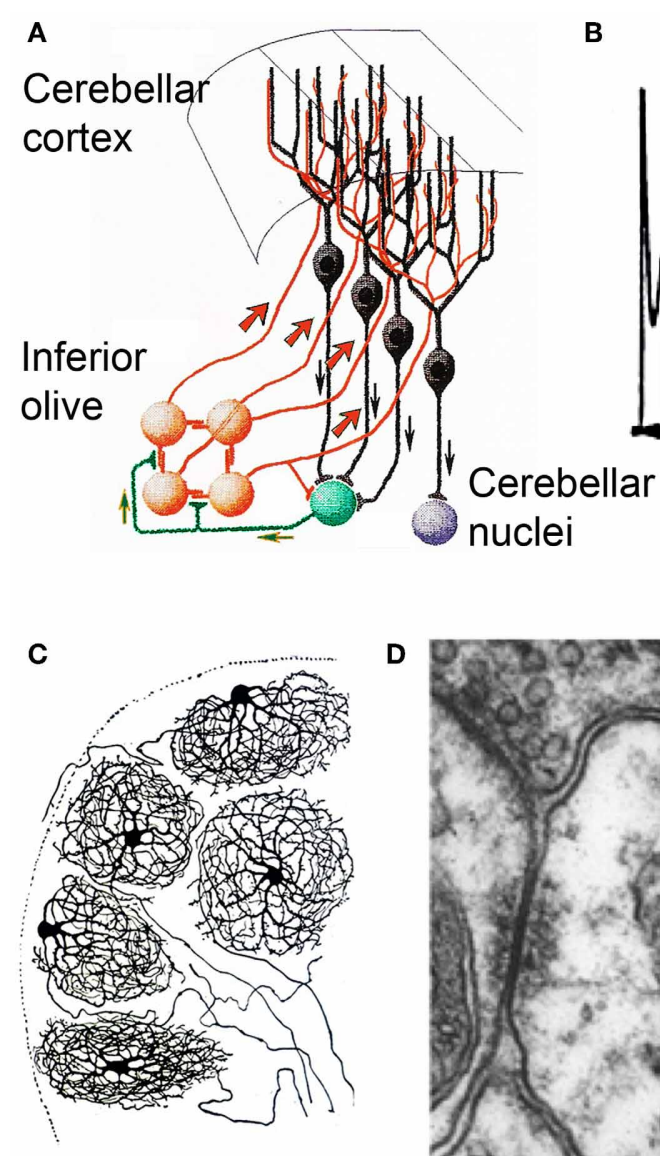

D

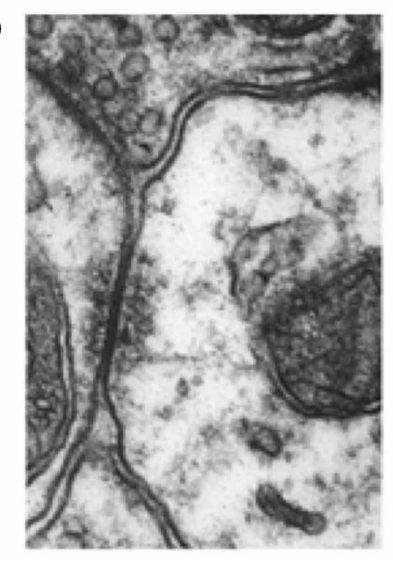

\section{Purkinje cell spikes}

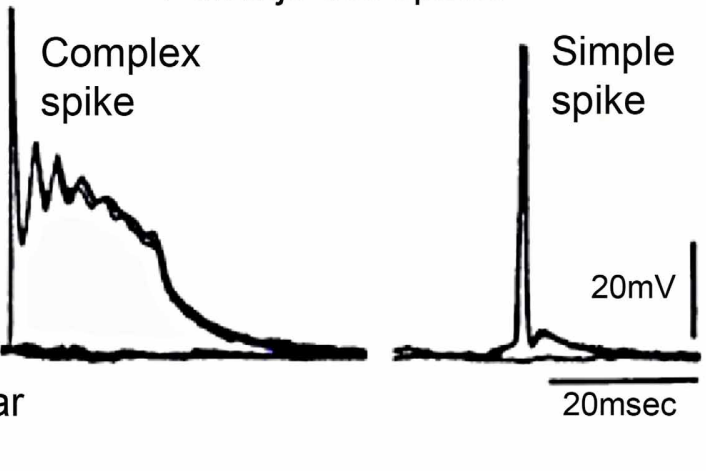

E

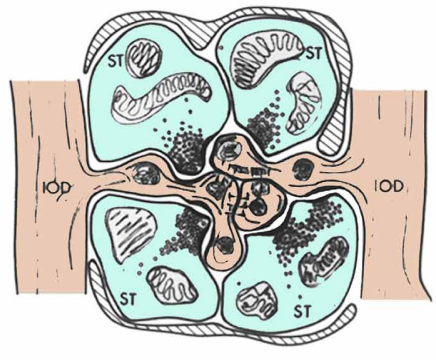

a

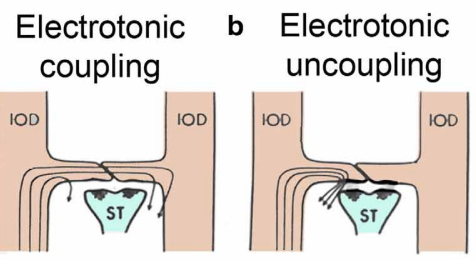

FIGURE 1 | Olivocerebellar circuit. (A) Cerebellar cortex. Inferior olive axons (IO, orange) activate Purkinje cells (black) through the climbing fibers and send collaterals to cerebellar nuclear cells (green) that feed back to $1 O$ and projection cerebellar nuclear cells (purple) (After Ramon y Cajal, 1911). (B) Intracellular recordings of an-all or-none complex spike elicited by climbing fiber stimulation and a simple spike elicited by mossy fiber activation. (C) Inferior olivary neurons (Ramon y Cajal, 1911). Note the spherical dendritic trees. (D) Electronmicrograph showing gap junction between spines of 10 dendrites within 10 glomerulus. Modified from Llinás et al. (1974). (E) Diagram of IO glomerulus. The center shows spines from 10 dendrites (IODs) coupled by gap junctions. (a) coupling current path between 10 dendrites, (b) current flow shunted when gabaergic synapses are active at the gap junction. (Modified from Llinás, 1974).
Purkinje cell synapse (Ramon y Cajal, 1911) (Figure 1A, black). This synapse is a one-to-one chemical junction and is all of IO origin, exclusively (Szentagothai and Rajkovits, 1959). This input establishing hundreds of junctions with the large spines in the main branches of the Purkinje cell dendritic tree. Activation of a climbing fiber elicits an all-or-none excitatory response in the Purkinje cells (Eccles et al., 1965, 1966a,b,c) (Figure 1B, left trace) later named a "complex spike," (Thach, 1968) as opposed to the simple spike produced by parallel fiber activation (Figure 1B, right trace). There are about ten times more PCs than IO neurons and so each IO neuron generates an average of ten climbing fibers (Armstrong and Schild, 1970). The PC axons, the only output of the cerebellar cortex, terminate in the cerebellar and related vestibular nuclei where they form inhibitory synapses (Ito and Yoshida, 1966) (Figure 1A). Cerebellar nuclei neurons are the only output of the cerebellum.

Concerning the cerebellar nucleus neurons they exist in two varieties with about half being excitatory and the other half inhibitory. The excitatory variety innervates brain stem, thalamus, and spinal cord via direct and indirect pathways. The inhibitory neurons return, in their entirety, to the centro-lateral IO where they form synapses in structures called "glomeruli" (Figure 1E) as well as with the dendritic tree directly (Sotelo et al., 1986; de Zeeuw et al., 1990a; Fredette and Mugnaini, 1991; Medina et al., 2002). Each IO glomerulus contains five to eight spines from dendrites of different IO neurons and support IO electrotonic coupling via gap junctions (Llinás, 1974; Llinás et al., 1974; Sotelo et al., 1974; de Zeeuw et al., 1990b) (Figure 1D). The degree of coupling is, thus, dynamically modulated by the inhibitory synaptic shunting (Figure 1E) (Llinás, 1974; Lang et al., 1996) as a feed back from the cerebellar nuclear output (de Zeeuw et al., 1990a, 1996).

\section{TIMING P ROPE R TIES OF THE OLIVOCEREBELLAR SYSTEM MOTOR COORDINATION AND TIMING}

Concerning motor coordination and timing three general issues are evident in the electrophysiology of the olivocerebellar system. (1) The system generates a timing signal that is inscribed in the 
intrinsic electrical properties of single IO (Figures 2-4) and cerebellar nuclear (Figure 5) neurons, (2) the organization of the nucleus via electrical coupling allows for synchronous multicellular temporal coherence that generates a close to simultaneous neuronal cluster activation (Figures 6, 7), and (3) due to the remarkable property of conduction isochronicity (Figure 8) the timing signal does not disperse against distance as it is conducted along the pathways carrying it to the final integration sites at cerebellar nuclear level. Each of these issues will be considered in turn.

\section{SINGLE CELL ELECTROPHYSIOLOGY}

With the exception described below, concerning two types of IO neurons, most of the olivocerebellar has been known to generate synchronous rhythmic activity attributed to the intrinsic oscillatory properties of the IO neurons (Llinás and Yarom, 1981a,b; Benardo and Foster, 1986; Bal and McCormick, 1997) and their multicellular synchrony supported by their electrotonic coupling (Llinás, 1974; Sotelo et al., 1974; Llinás and Yarom, 1981a,b; Lampl and Yarom, 1997; Makarenko and Llinás, 1998; Yarom and Cohen, 2002). Recently, asynchronous release of GABA has been reported to determine an inhibitory regulation of electrical coupling of neurons in the IO (Best and Regehr, 2009).

Such intrinsic oscillatory properties are supported by a set of voltage-dependent calcium and potassium conductances (in addition to those involved in action potential generation) enabling IO cells to oscillate and fire rhythmically at $1-10 \mathrm{~Hz}$. These conductances include a high-threshold $\mathrm{Ca} 2+$ conductance, a low-threshold $\mathrm{Ca} 2+$ conductance, a Ca2+-activated $\mathrm{K}+$ conductance, and a hyperpolarization-activated cationic conductance (Llinás and Yarom, 1981a,b, 1986; Bal and McCormick, 1997). There is as mentioned above, a separate group of IO neurons with quite different electrical properties.

\section{Two basic 10 neuron types}

An important, but often forgotten, aspect of IO function is the fundamental differences between two parts of the olive, what may be called the principal olive (PO) represented by the three main nuclei (lateral medial and central) and the Dorsal Cap of Kooy (DCK). Morphologically PO neurons are characterized by a spherical dendritic tree (Figure 1C) while the dendrites of DCK neurons have a bipolar-like arrangement that extended farther away from the soma (Urbano et al., 2006). The two different morphological type neurons present in the IO are also electrophysiologically distinct.

The PO comprises most of the IO neurons, are concerned with limb and digit movements and to the so-called "physiological tremor" i.e., the non-continuous nature of motor organization (Llinás, 1991; Welsh and Llinás, 1997). This tremor supports the timing of motor execution in all systems other than the oculomotor. The functional character of PO neurons can be easily observed by measuring, for instance, the velocity of voluntary human finger movements (Vallbo and Wessberg, 1993) that occur at a close to constant of $8-10 \mathrm{~Hz}$ steps independently of movement speed. Synchronous IO oscillations have been shown to modulate periodic vibrissal movements (Lang et al., 2006) in the same frequency range. Electrophysiologically, such IO neurons are characterized by their ability to generate high-threshold Figure 2A and "low-threshold" calcium spike as recorded in vitro Figure 2B (Llinás and Yarom, 1981a,b). The latter is generated by the activation of both T-type calcium channels (Cav3.1) and Ih potassium currents (Llinás and Yarom, 1981a,b, 1986; Bal and McCormick, 1997; Lampl and Yarom, 1997), which limits their frequency to $8-10 \mathrm{~Hz}$. PO neurons are characterized by subthreshold oscillations at $8-10 \mathrm{~Hz}$ that are very stable (Figure $2 \mathrm{C}$ ). In vivo intracellular recordings from IO neurons have shown transient subthreshold oscillations at $6-12 \mathrm{~Hz}$ with spikes generated on the depolarization phase of the oscillations (Chorev et al., 2007). A single action potential in the IO triggers a burst of axonic spikes. The properties of the spike burst are modulated by the phase (Mathy et al., 2009) and or amplitude (Bazzigaluppi et al., 2012) of the subthreshold oscillations.

The DCK is a smaller nucleus that is involved with the organization of eye movements. These neurons lack both T-type calcium
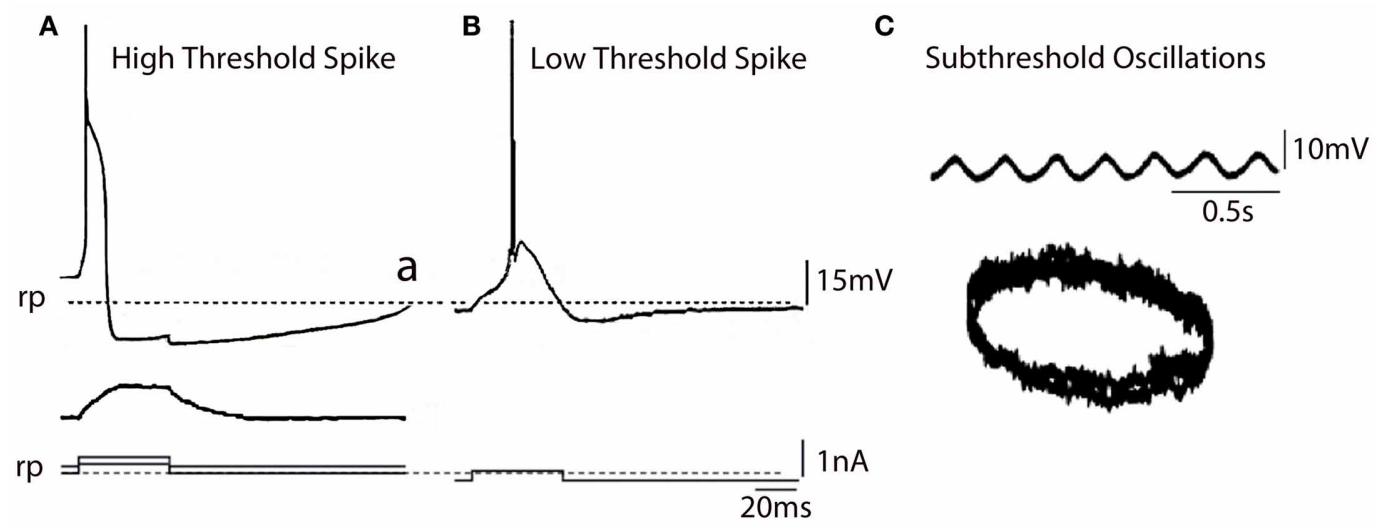

$2 \overline{0 m s}$

FIGURE 2 | 10 Electrophysiology. (A) In vitro intracellular recordings from IO neuron showing high threshold spike (a) activated by an outward pulse from a depolarized potential with respect to rest (broken line) the same outward pulse delivered from the rest potential (broken line) did not elicit a spike (b). (B) Same pulse as in (A) delivered from a hyperpolarized membrane potential level generated a low voltage activate spike (Modified from Llinás and Yarom, 1981a,b). (C) Subthreshold membrane oscillation recorded intracellularly from an 10 neuron and associated Lissajeux image demonstrating oscillatory stability. (Modified from Llinás and Yarom, 1986). $\mathrm{rp}$, resting potential. 


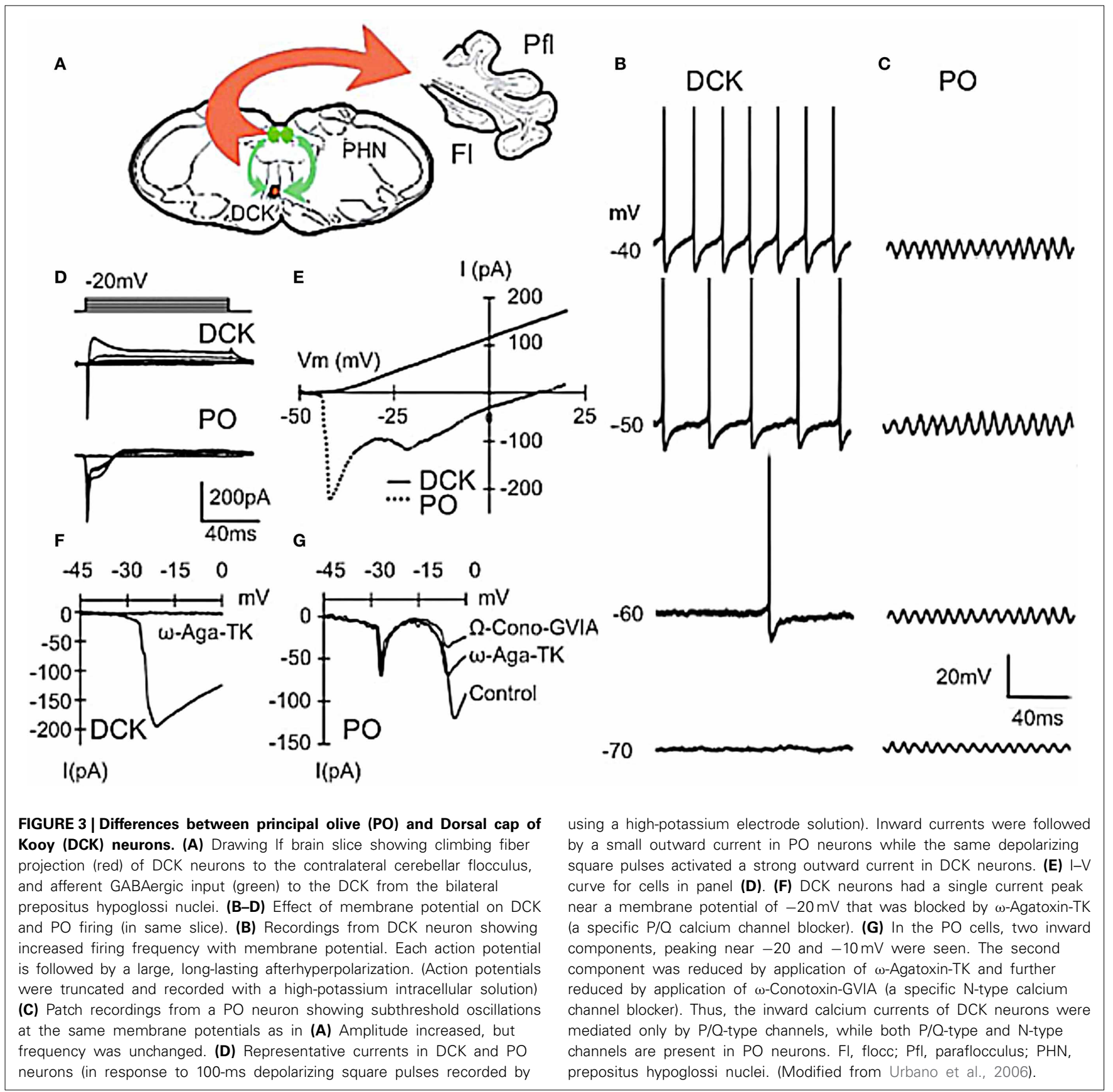

channels and the Ih potassium current (Urbano et al., 2006) underlying the intrinsic subthreshold oscillation characteristics of PO neurons and so do not display subthreshold oscillatory behavior. They are, however, electrotonically coupled, but only to each other, shunning contacts with their oscillatory counterpart (Urbano et al., 2006). These fundamental differences go a long way toward addressing the apparent functional inconsistencies that have plagued the field of cerebellar motor control and, more importantly, give further support to the findings concerning the time binding proposal for non-ocular motricity (Carpenter, 1977; Farmer, 1998; Llinás, 2009).
Because DKC Neurons do not oscillate one of the arguments often voiced against the timing hypothesis of IO function has related to the absence of the physiological tremor in the oculomotor system (Carpenter, 1977). Thus, as stated above, while physiological tremor is observed in somatomotor systems (Llinás, 1991; Vallbo and Wessberg, 1993; Lang et al., 2006), where it has been shown to play an important role in motor binding by providing coherent activation of the motoneuronal pools responsible for motor execution, such physiological tremor is conspicuously absent in ocular motricity. Indeed, it has been known for many years now (Carpenter, 1977) that the oculomotor system 


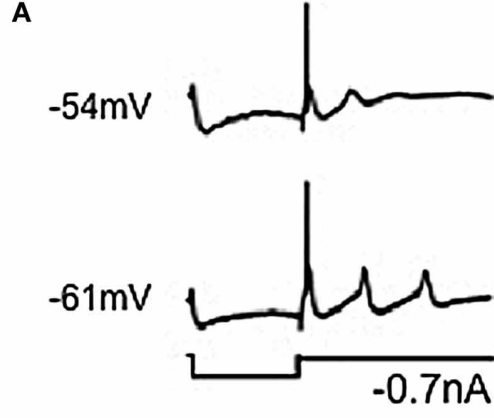

C

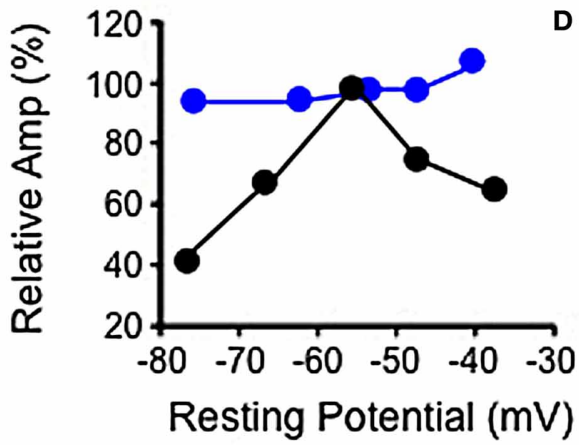

E

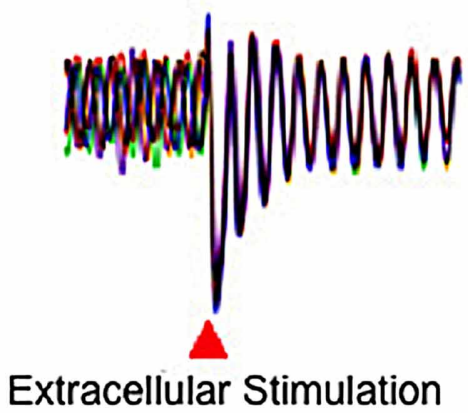

FIGURE 4 | Electrophysiological properties of 10 in wild-type and mutant mice. (A,B) Hyperpolarizing current injection elicited a low threshold spike from $1 \mathrm{O}$ cell in slice from wild-type mouse (A), but not from mutant mouse (B) at resting potentials of -54 and $-61 \mathrm{mV}$. Subthreshold rebound mediated by Ih was present in the mutant mouse. (C) Plot showing modulation of subthreshold sinusoidal oscillation (SSTO) amplitude by membrane potential in wild-type (black) but not in mutant
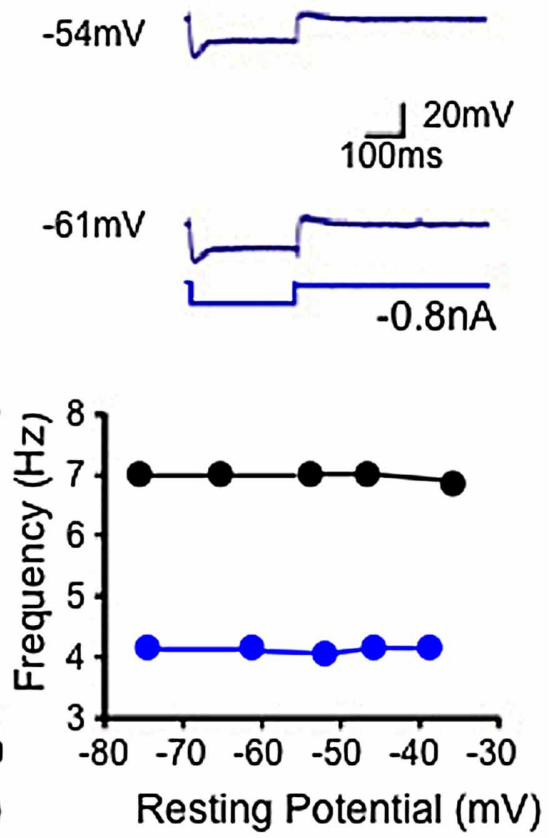

$\mathbf{F}$

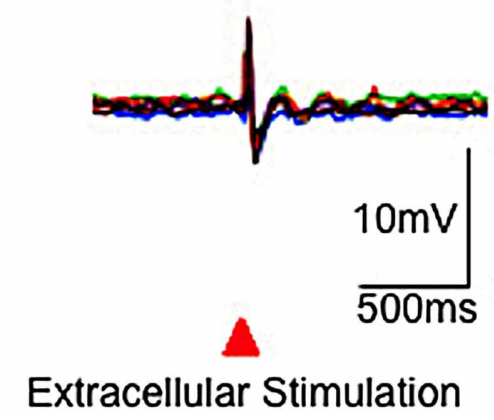

(blue) mice. (D) Frequency of SSTO was lower in mutant than in wild-type mice but neither was modulated by membrane potential. (E,F) Superposition of six traces showing SSTO recorded from single 10 neuron in wild-type (E) or mutant (F) mouse. Extracellular stimulation lead to phase reset of SSTO in 10 cell in slice from the wild-type mouse. Such stimulation had a minor, if any, effect in the mutant mouse (F). (Modified from Choi et al., 2010). is capable of both smooth pursuit (an object is followed on a moving trajectory) and saccadic eye movements (the eye position is quickly reset having reached maximal displacement from its central orbital position).

The findings of a recent study comparing the electrophysiological properties of PO and DCK neurons helps explain the discrepancies observed between somato-motor and oculomotor cerebellar control (Figure 3). DCK neurons, identified using Biocytin during patch recordings (Urbano et al., 2006), responded differently to current injection than do PO cells. They did not present an h-current- dependent "depolarizing sag" during hyperpolarization and the T-current-dependent rebound of membrane potential was absent. When depolarized, DCK fired at a much higher frequency than PO neurons. The average frequency of DCK firing could reach gamma-band frequencies $(>30 \mathrm{~Hz})$ while $\mathrm{PO}$ neurons only reached thetaband range $(4-8 \mathrm{~Hz})$. The same frequency range of membrane potential events was observed using voltage sensitive dye imaging. We stained transversal slices using the voltage-sensitive dye di-4ANEPPS and used a bipolar electrode to deliver a pair of stimuli $(50 \mathrm{~Hz}, 2$ shocks of $200 \mu \mathrm{s}$ of duration) at the edge of the DCK nucleus. After such stimulation the entire DCK nucleus depolarized rhythmically with peaks of activity every $1.5 \mathrm{~s}$. 

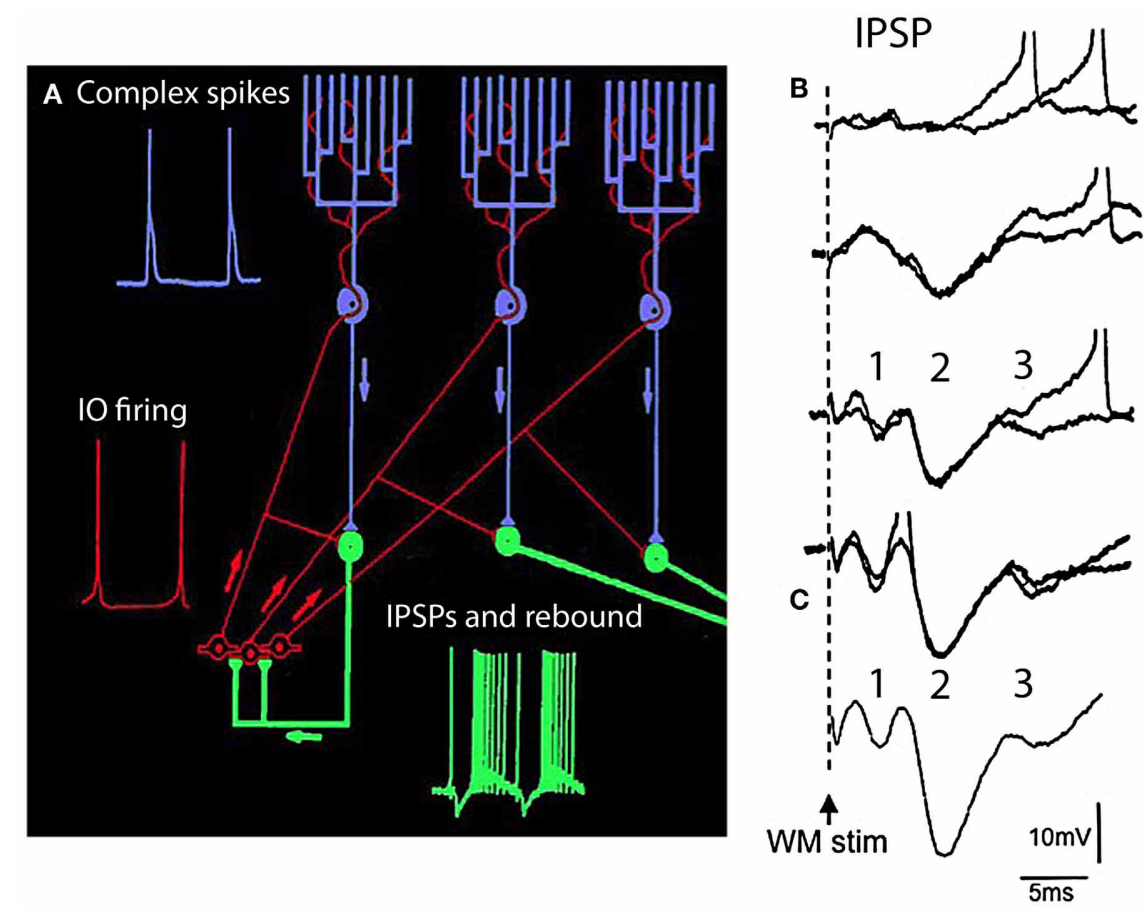

FIGURE 5 | The olivocerebellar loop circuit. (A) Diagram of olivocerebellar circuit. Action potentials in 10 neurons (red) are generated at the crest of the subthreshold oscillations; example of subthreshold oscillations is shown in Figure 2C. These elicit complex spikes in Purkinje cells (green) and activate cerebellar nuclear cells (purple and yellow). Purkinje cell output is inhibitory to cerebellar nuclear cells where the IPSPS trigger rebound firing in cerebellar nuclear cells. Arrows indicate direction of action potential conduction. (B,C) Synaptic potentials and firing of cerebellar nuclear cells. White matter stimulation (WM stim) at increasing stimulus strength elicits graded EPSP-IPSP sequences. The first sequence (1) is due to direct stimulation of mossy fiber collaterals (EPSP) and Purkinje cell axons (IPSP). The second sequence is due to activation of the climbing fiber system (2) the Purkinje cell IPSP was strong enough to activate the rebound response (3 and spikes). (C) Average of 10 responses showing the timing of the EPSP-IPSP sequences. (Modified from Llinás and Muhlethaler, 1988).

\section{PO Neuron Oscillation are Dynamically Regulated by P/Q-Type and T-Type Calcium Channels}

Concerning mechanisms responsible for membrane potential oscillation in PO neurons, one of the remarkable properties is the set of ionic conductances that generate such electrical activity. Thus, the electrophysiological properties of IO neurons have recently been investigated using knock out $(\mathrm{KO})$ mice that lacked the gene for the pore-forming $\alpha 1 \mathrm{G}$ subunit of the T-type calcium channel $\left(\mathrm{CaV} 3.1^{-/-}\right)$and their littermate wild type (WT) mice (Choi et al., 2010). The low-threshold calcium spike and the sustained endogenous oscillation following rebound potentials were absent in $\mathrm{IO}$ neurons from $\mathrm{CaV} 3 \cdot 1^{-/-}$mice.

In addition to spikes, PO neurons support spontaneous subthreshold membrane potential oscillations near $10 \mathrm{~Hz}$ (see Figure 2C) (Benardo and Foster, 1986; Llinás and Yarom, 1986). It has been proposed that calcium current and calcium-activated potassium current may be account for the oscillatory behaviors of IO neurons (Llinás and Yarom, 1981a,b, 1986). The other group of mice lacked the gene for the pore-forming $\alpha 1 \mathrm{G}$ subunit of the T-type calcium channel $\left(\mathrm{CaV} 3.1^{-/-}\right)$. In these mice the LTS, activated as a rebound from a hyperpolarizing square current pulse, was absent (compare Figures 4A,B) but the HTS was not affected. Although the rebound activity mediated by the hyperpolarization-activated cation current (Ih) was still present in $\mathrm{IO}$ neurons from CaV3.1 $1^{-/-}$mice, it was not strong enough to evoke sodium spikes (Figure 4B). IO neurons from these mice also showed altered patterns of subthreshold oscillations and the probability of their occurring was only 15\%, significantly lower than the one found in wild-type animals (78\%). In addition, the low-threshold calcium spike and the sustained endogenous oscillation of rebound potentials were absent in IO neurons from these mice. The results from studies of these $\mathrm{KO}$ mice suggest that both $\alpha 1 \mathrm{~A}$ P/Q- and $\alpha 1 \mathrm{G}$ T-type calcium channels are required for the dynamic control of IO oscillations.

No significant changes in the input resistance, time constant, and capacitance of membrane were observed between IO neurons recorded in either mutants or WT mice (Choi et al., 2010). These findings indicate that the $\alpha 1 \mathrm{~A} \mathrm{P} / \mathrm{Q}$-type calcium channels are involved in the generation of HTS and calcium conductance by $\alpha 1 G$ T-type calcium channels also play a crucial role in the generation of LTS.

In WT mice IO cell oscillation modulate spike initiation, and so action potentials are normally generated at the crest of such oscillations and fire at $1-10 \mathrm{~Hz}$. This intrinsic rhythm is thus entrained with the speed of movement execution as mentioned above. Moreover, the phase of subthreshold oscillations may be 
A

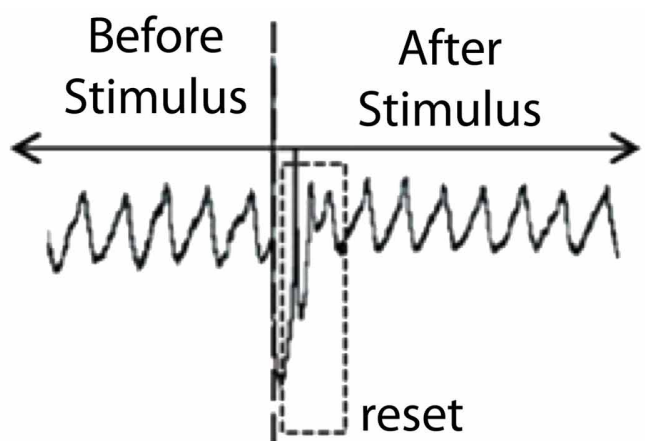

B

C

Six individual traces

\section{I}

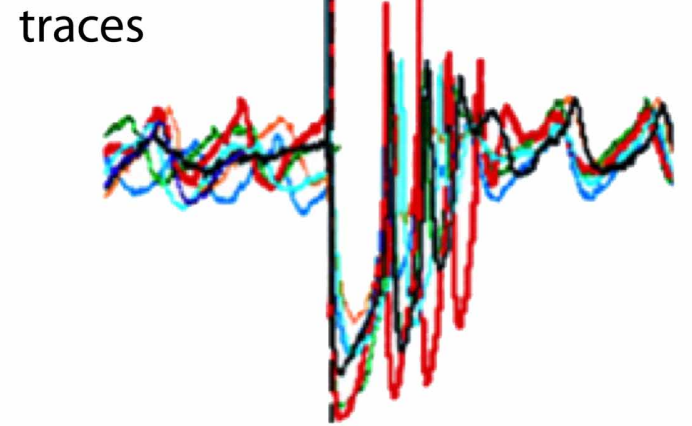

Power Spectra

\section{Mean of six traces}

\section{spontaneous oscillations, with stimulus}

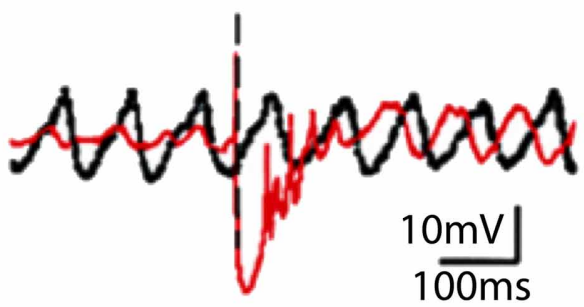

Power Spectra

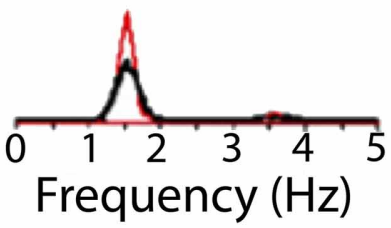

FIGURE 6 | IO spontaneous and stimulus-evoked oscillations. (A) Intracellular recording of spontaneous oscillations at $2 \mathrm{~Hz}$ interrupted by an extracellular stimulus. After extracellular stimulation the oscillations disappeared for $750 \mathrm{~ms}$ (boxed area) and then resumed. (B) Left. Superimposition of six individual intracellular traces (each a different color) of stimulus-evoked oscillations recorded from the same cell. Right. Power spectra. The frequency of stimulation-evoked oscillation was the same $(2.0 \mathrm{~Hz})$. Oscillations are clear after the stimulus-induced reset but can be barely detected before the stimulation. (C) Superposition of average of six traces of stimulus-evoked oscillations (red) and spontaneous oscillations (black). The stimulus-evoked and spontaneous oscillations have the same frequency. Calibration, $1 \mathrm{mV}$; (A) $1 \mathrm{~s}$; (B) $415 \mathrm{~ms}$; (C) $500 \mathrm{~ms}$. (Modified from Leznik et al., 2002). influenced by subthreshold activity, as shown in Figures 4E,F). Indeed, extracellular local electrical stimuli, or strong excitatory synaptic input will reset the phase, but not the amplitude or frequency, of subthreshold oscillations (Leznik et al., 2002).

\section{ELECTROTONIC COUPLING}

Concerning the electrical coupling, as in other CNS structures (Bennett, 2000), gap junctions constitute the main communication pathway between the IO neurons (Sotelo et al., 1974; de Zeeuw et al., 1996; Devor and Yarom, 2002). Such electrotonic coupling has been assumed to play a crucial role in synchronizing IO oscillations and in generating groups of concurrently oscillating neurons (Llinás and Yarom, 1986). This coupling was also assumed to be controlled by return glomerular inhibition (Llinás, 1975). IO afferents were, in fact, found to modulate the efficiency of electrotonic coupling via inhibition at the glomerulus. The pathway function is actually supported, as stated above, by the cerebellar nuclear GABAergic neurons (Sotelo et al., 1986; Fredette and Mugnaini, 1991; de Zeeuw et al., 1996; Medina et al., 2002). These neurons represent $50 \%$ of the total neuronal population in such nuclei giving some measure of the importance of this feedback inhibitory pathway. Accordingly, it was determined that such input can control the degree and distribution of synchronous oscillatory activity in the IO nucleus (Leznik and 
A Intracellular Signal (black), Optical Signal (red)

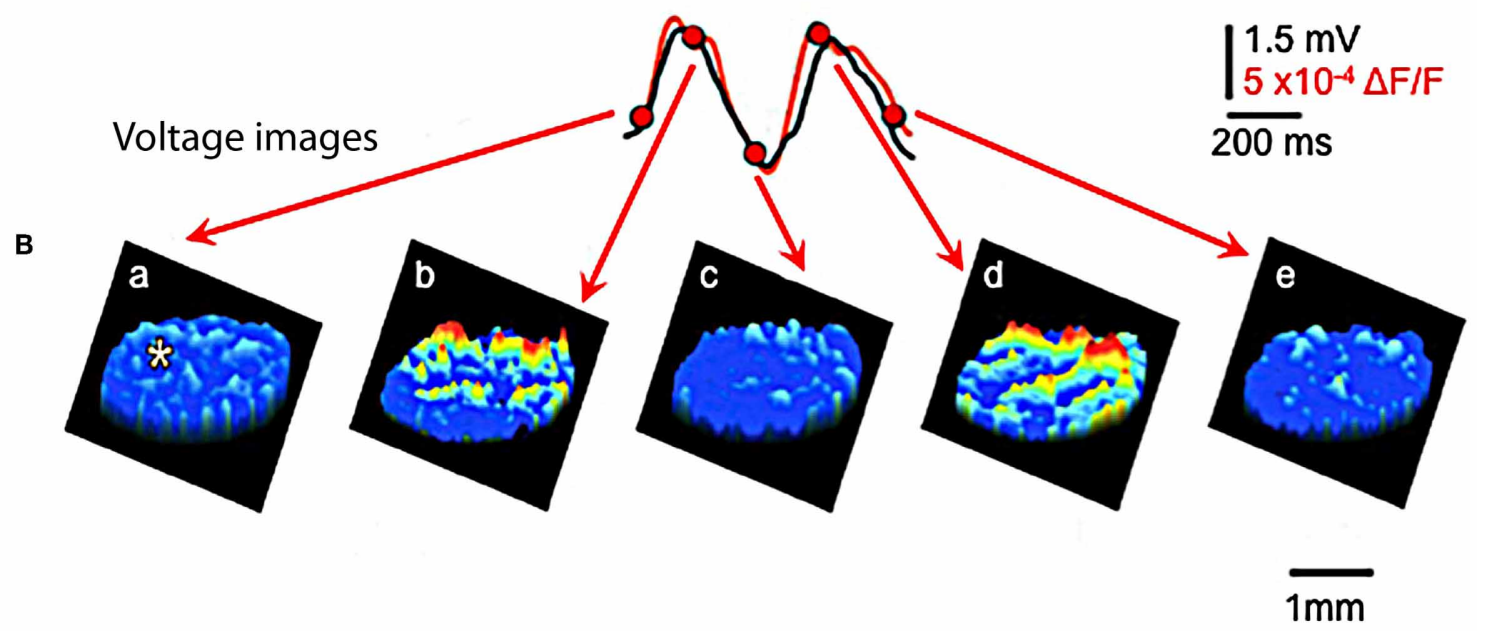

FIGURE 7 | Optical and intracellular recordings in brainstem slice. (A) Recordings of $1 \mathrm{O}$ subthreshold oscillations are quite similar using optical (red) and using intracellular voltage (black) methods. (Recording site indicated by asterisk in first image panel in B). (B) Spatial profiles of optically recorded oscillations at five times during the oscillation shown in panel (A). (Modified from Leznik and Llinás, 2005).

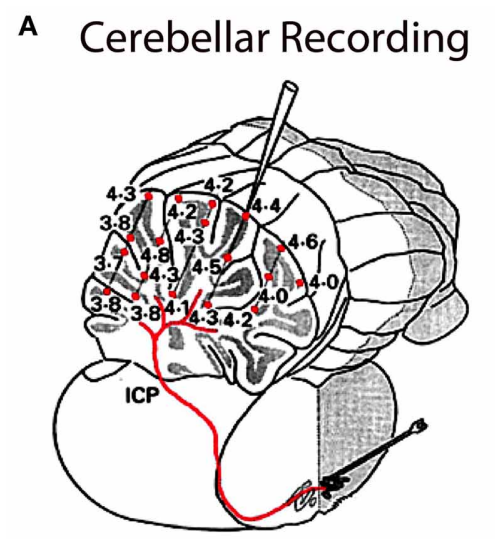

B

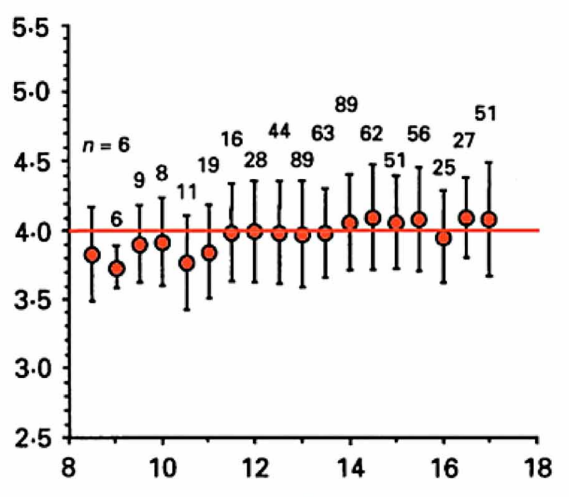

C

\section{Conduction Velocity}

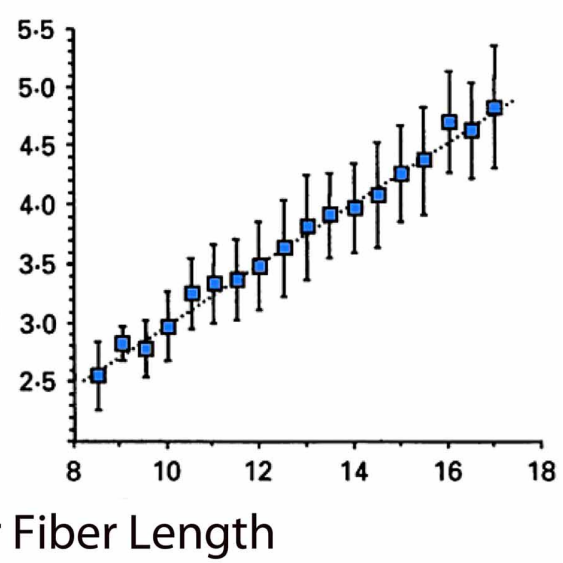

FIGURE 8 | Olivocerebellar conduction times. (A) Drawing of cerebellum showing conduction times for evoked complex spikes (parasagittal plane $4 \mathrm{~mm}$ from midline) in an in vivo preparation. (B) Plot of mean conduction time ( \pm sem) as a function of olivocerebellar fiber length $(0.5 \mathrm{~mm}$ bins) showing that conduction time was independent of distance between 10 and individual Purkinje cell. (C) Plot showing close to linear relationship between mean conduction velocity $( \pm$ sem) and fiber length. (Modified from Sugihara et al., 1993).
Llinás, 2005) and the cerebellar cortex (Lang et al., 1996; Lang, 2001, 2002). Moreover, dynamic groups of IO neurons oscillating in-phase can synchronously activate a population of PCs and thereby control patterns of synchronous activity in the cerebellum during motor coordination (Welsh et al., 1995). Models of IO cells that includes conductances as well as gap junctions explores the interaction of coupling strength, membrane potential level, and conductance modulation in IO synchronization at the network level (Manor et al., 1997; Schweighofer et al., 1999, 2004a,b; Manor et al., 2000; Jacobson et al., 2008; Torben-Nielsen et al.,
2012) and effect on the climbing fiber burst (De Gruijl et al., 2012).

As in other brain regions the gap junctions are formed by connexin 36 (Cx36) (Condorelli et al, 1998; Belluardo et al., 2000; Rash et al., 2001). Yet, in Cx36 knock-out mutant mice subthreshold oscillations are present (Long et al., 2002). This has been shown to be due to morphological and electrophysiological compensations in the mutant IO neurons making them more excitable (De Zeeuw et al., 2003). A recent study utilizing tracers and paired electrophysiological recordings has shown 
that the coupling between IO neurons is highly variable (Hoge et al., 2011). This introduces another important parameter in considering IO function in motricity.

\section{Visualization of 10 cluster activity}

Although synchronized IO oscillations are a neuronal ensemble event, they have been studied primarily on a single-cell level and no information has been available about their spatial profiles. Thus, an attempt was made to address this issue by utilizing voltage-sensitive dye optical imaging (Leznik and Llinás, 2005; Leznik et al., 2002). This technique is presently the methodology of choice in studying the geometrical distribution of activity in a large neuronal ensemble (see, for instance, Ebner and Chen, 1995). We have shown that ensemble oscillations in the IO originate in synchronized activity clusters, where each cluster is a localized functional event composed of hundreds of cells. Given the distribution of complex spike activity in the cerebellum cortex, we have proposed that these clusters are very likely to be responsible for the synchronized activation of the PCs observed in previous in vivo multielectrode experiments (Lang et al., 1996). Furthermore, when comparing our experimental results with those obtained by computational modeling of IO neuronal ensembles endowed with oscillatory electrical properties and electrotonic coupling (Makarenko and Llinás, 1998; Velarde et al., 2002), we could show that neuronal oscillatory clustering is a direct consequence of the combined electrotonic/intrinsic properties of coupled IO neurons (Leznik et al., 2002).

While electrical recording of IO neurons in vitro had indicated the possibility that electrically coupled IO cells could actually cluster into synchronized ensemble neuronal groupings, there was no direct demonstration of such dissipative structures. In searching for such dissipative structures, voltage-sensitive dye imaging of oscillatory activity was attempted and successfully implemented in rodent IO slices (Leznik et al., 2002). Thus, spatio-temporal profiles of ensemble IO oscillations were unambiguously observed following IO electrical stimuli. The stimulation serves to both reset the phase of subthreshold oscillation and to entrain a large proportion of neurons to in-phase oscillations. Indeed, synchronization of oscillatory activity over the IO network increased the amplitude of the optical signal to a level that could be detected easily with our imaging set up. Such oscillatory reset was also observed with intracellular recordings from IO neurons (Figures 4, 6). The optically recorded oscillatory clusters have a dynamic spatial organization, and their amplitude depends on the oscillation phase such that they embraced the largest area during the upward phase of the oscillations. Each cluster consisted of a core region and the adjoining area. The core region demonstrated a close to constant size, but the extent of the adjoining area was found to be phase-dependent.

Direct calculation of core and maximum area (i.e., the core region plus the adjoining area at its utmost extent) for several representative clusters gave a mean core area and a mean maximum of several hundred $\mu 2$. Because IO clusters are three-dimensional structures, observed in this case as a planar structure indicate that in depth they comprise hundreds of cells. Thus, our optical data indicate that at the network level, the IO nucleus is organized in functionally coupled tridimensional activity clusters. Each cluster is comprised of several hundred cells, which may act in unison to activate groups of thousands of cerebellar PCs simultaneously in agreement with the multiple electrode recordings observed previously.

In conclusion, the dimensions of clusters are probably determined by the IO electrical coupling coefficient, and thus by the magnitude and distribution of the return inhibition from the cerebellar nuclear feedback, which has been demonstrated in previous in vivo experiments (Ruigrok and Voogd, 1995; Lang et al., 1996) and supported with mathematical modeling (Leznik et al., 2002; Velarde et al., 2002).

\section{THE CLIMBING FIBER CONDUCTION ISOCHRONICITY}

From another perspective, while the temporal distribution of activity is well-demonstrated at the olivary level, one may wonder about the time dispersion produced by the olivocerebellar pathway given the different distances between the IO axons and their target PCs. However, if isochronicity is present, then the conduction time between an IO neuron and its PC should be close to uniform and independent of the distance such a signal had to travel. This issue is particularly significant given that the folded nature of such a cortex can increase the path length to the PCs by more than $50 \%$. Furthermore, the correction of the conduction velocity needed to insure synchronicity should be related linearly to distance. This was, in fact, shown to be the case. The time dispersion for a nearly $4 \mathrm{~ms}$ conduction time was plus or minus $500 \mu$ s to any regions of the cerebellar mantle, regardless of the distance between the IO and the cerebellar cortex at the bottom or top of the of the deep cerebellar folia or at any point in between (Sugihara et al., 1993). The results were based on complex spike latency from 660 different PCs from 12 rats (Figure 8).

Since our original demonstration, this isosynchronicity has been confirmed in further experiments with other cerebellar systems (Ariel, 2005; Brown and Ariel, 2009). A similar finding concerning conduction isochronicity has also been observed in the thalamocortical system and has been interpreted, as in the case of the olivo-cerebellar system, as a mechanism for temporal coherence. In this case, such timing has been related to the temporal coherence associated with cognitive binding (Engel et al., 1997; Salami et al., 2003; Chomiak and PetersHu, 2008; Vicente et al., 2008).

Therefore, the results indicated that the cerebellar cortex, while being deeply folded anatomically behaves, functionally, as an isochronous sphere as far as the olivocerebellar system is concerned. Further, such isochronicity is actually related to the onset time and duration required for proper motor execution (Welsh et al., 1995).

\section{THE OLIVOCEREBELLAR SYSTEM AND ERROR SENSING}

Finally, the issue of error sensing, which was previously of great interest to cerebellar physiologists, has been treated in detail in excellent reviews concerning IO function (Simpson et al., 1996; De Zeeuw et al., 1998). My personal view is that the error-sensing signal that is often observed in climbing fiber responses-while being a very important functional phenotype-may not be "the central cerebellar function" as some authors claim. From my perspective, the high probability of complex spike activation in 
relation to unexpected error signals correlates well with such events simply because it is easy to detect. This is the case because climbing fiber activation is massive both when a large reset of the oscillatory phase occurs (Makarenko and Llinás, 1998; Leznik et al., 2002; Chorev et al., 2007; Khosrovani et al., 2007; see also Van Der Giessen et al., 2008 for the connexin 36 role in this large reset), and when a massive temporal reorganization of motor pattern activity is required.

\section{Experimental findings}

This question was addressed in studies rodent brainstem slices. In agreement with previous intracellular results (Llinás and Yarom, 1986), an extracellular stimulation given at the dorsal border of the IO nucleus generates a full action potential demonstrate that if the cell was oscillating at the time of the stimulus, its oscillations are stopped momentarily, but resumed with a different phase shortly after the stimulation (Llinás et al., 2002). Moreover, in later experiments, it was also determined that such extracellular stimulation may reset the phase without affecting the amplitude or frequency of the subthreshold oscillation (Leznik and Llinás, 2005), and that for most cells recorded, this phase reset could be observed repeatedly with subsequent stimuli (Figure 3 ). However, the most surprising property discovered was the fact that the oscillation phase shift was remarkably constant and independent of the original phase moment at which the stimulus was delivered.

This constant phase shift is of central importance in defining IO function, as it gives a clear time constraint to the functional states generated by the neuronal ensemble. The reset property of the IO circuit can thus be considered as the main component in the large correction that must be generated when a movement error occurs. This is best illustrated by the fast recovery that we all experience when tripping during locomotion and the fact that we do not fall, while robots do, under similar circumstances.

The issue of error correction has been studied elegantly under conditions where random stimuli require temporal resting under circumstances of robust activation of the cerebellar system (Schweighofer et al., 2004a,b); however, this issue must be addressed further as other views are also clearly present (Gilbert and Thach, 1977; Horn et al., 2004; Catz et al., 2005; Kojima et al., 2010; Popa et al., 2012, 2013). The image one has is of the activation of a very large population of Purkinje cells that mediate a rapid inhibition of the inhibitory cells of the nucleo-olivary pathway, resulting in increased coupling at the olivary level. This event will produce a large and coherent activation of IO neurons; thus, an increased probability of PC complex spike activation ensues. In short, then, error correction is one mode, but not the main mode of IO function.

\section{THOUGHTS ON THE FUNCTIONAL SIGNIFICANCE OF TWO DISTINCT OLIVOCEREBELLAR SYSTEMS}

The rather remarkable differences observed in both the electrophysiology and morphology of these two types of IO neurons clearly implies that the IO nucleus must operate in at least two different modes. While with hindsight we now better understand the problems presented by the lack of oscillatory behavior in the oculomotor system and the presence of physiological tremor in the somato-motor system the findings reported here requires a hypothesis that addresses the necessity of two types of IO neurons in the organization of coordinated motricity.

While the importance of a timing signal has been theoretically assign to the requirements of motor temporal binding (Welsh and Llinás, 1997) by allowing time coherence of motoneuron activation to provide a basic element for motor coordination, a similar case may be made for the oculomotor system. So what would be the difference between somatic and ocular motricity that would require such dramatic functional differentiation? One possible hypothesis relates to the multiple joint organization of the somato-motor system as opposed to the single joint organization of the oculomotor system. In the former case multiple parameters corresponding to different coordinate systems must operate in unison to attain coordination. To this parameter is added muscle feed back that operates in all myotatic reflexes where muscle spindles are simultaneously informing the CNS about the position and rate of movement of each segment of any of our multi-jointed limbs. Because of the tremendous complexity afforded by such massive co-activation of motoneuron pools the temporal requirements become astronomically complicated and a welcome control approach might be to restrict movement to the ballistic properties that we know characterize somato-motor movements (Welsh and Llinás, 1997). By contrast, oculomotor activity does not require the ballistic approach to motor generation since all the parameters are regulated to only one vector in tridimensional space. To this parameter is added the fact that eye movements require a degree of precision not usually demanded of the somato-motor system. Indeed eye movement fixation is only modulated by the microsacadic system that operates at $0.2^{\circ}$ in amplitude in an open loop mode. The somatomotor system is far less precise and must operate under conditions where the movement load and momentum vary continuously. For example, as we reach, hold, and lift objects, masticate hard or soft materials, throw a projectile, or return a fast serve with a tennis racket.

In short, we may consider the enormous difference in motor organization as the evolutionary pressure that ultimately determined the motor organization of these two different motor strategies as the root for the very crisp differences in the electrophysiological properties of these two different types of IO neuron.

\section{CONCLUSIONS AND IMPLICATIONS}

Four main issues have been addressed in this short paper concerning the functional organization of the olivo-cerebellar system. (1) The olivocerebellar system seems to be related centrally to the control of motor timing. It's exceptional neuronal characteristics and the network properties that it supports make the olivo-cerbellar system a unique control system, where timing seems to be a central theme. (2) The combination of strong and rather stereotyped intrinsic electrical properties with electrical coupling among the neuronal elements allows the synchronous activation of clusters of neurons. Further, feedback inhibition provides the dynamic variance of the membership of such coupled clusters. (3) The very fundamental property of the resetting of the phase of groups of neurons by a stimulus, such that the new phase is coherent and independent from the original phase, makes this event truly spectacular. (4) When movements require 
truly continuous control and the issues if multi-joint dynamics are not considered, the IO generates non-oscillatory behavior, as is the case in eye movement kinetics. These four elements give the IO a very powerful set of network properties allowing not only the temporal control of many variables simultaneously, as occurs during motor control, and the possibility of rapid correction in the presence of unexpected events that require rapid global motor correction, but also the possibility of the smooth control that allow eye movement pursue of object displacement in the visual field.

Finally, nature has evolved a mechanism by which this very elaborate cluster dynamic generating system can transmit the timing sequences into a folded cortical geometry, without differential conduction time aberrations, and terminate its path by generating the most powerful synapse in the CNS. If this were not sufficient, the neurons it activates are the largest in the brain, receive just one such climbing fiber afferent, and its output is inhibitory (Ito and Yoshida, 1966). And so, nature has devised one of its most conserved neuronal systems to control motricity by inhibition, a very fitting attribute because it is by selection, via inhibition that the most elaborate neuronal patterns are generated in the CNS.

\section{REFERENCES}

Ariel, M. (2005). Latencies of climbing fiber inputs to turtle cerebellar cortex. $J$. Neurophysiol. 93, 1042-1054. doi: 10.1152/jn.00132.2004

Ariens-Kappers, C. U., Huber, G. C., and Crosby, E. C. (1936). The Comparative Anatomy of the Nervous System of Vertebrates Including Man. New York, NY: Macmillan.

Armstrong, D. M., and Schild, R. F. (1970). A quantitative study of the Purkinje cells in the cerebellum of the albino rat. J. Comp. Neurol. 139, 449-456. doi: $10.1002 / \mathrm{cne} .901390405$

Bal, T., and McCormick, D. A. (1997). Synchronized oscillations in the inferior olive are controlled by the hyperpolarization-activated cation current $\mathrm{I}(\mathrm{h})$. J. Neurophysiol. 77, 3145-3156.

Bazzigaluppi, P., De Gruijl, J. R., van der Giessen, R. S., Khosrovani, S., De Zeeuw, C. I., and de Jeu, M. T. (2012). Olivary subthreshold oscillations and burst activity revisited. Front. Neural Circuits 6:91. doi: 10.3389/fncir.2012.00091

Belluardo, N., Mudo, G., Trovato-Salinaro, A., Le Gurun, S., Charollais, A., SerreBeinier, V., et al. (2000). Expression of Connexin 36 in the adult and developing rat brain. Brain Res. 865, 121-138.

Benardo, L. S., and Foster, R. E. (1986). Oscillatory behavior in inferior olive neurons: mechanism, modulation, cell aggregates. Brain Res. Bull. 17, 773-784. doi: 10.1016/0361-9230(86)90089-4

Bennett, M. (2000). Electrical synapses, a personal perspective (or history). Brain Res. Brain Res. Rev. 32, 16-28. doi: 10.1016/S0165-0173(99)00065-X

Best, A. R., and Regehr, W. G. (2009). Inhibitory regulation of electrically coupled neurons in the inferior olive is mediated by asynchronous release of GABA. Neuron 62, 555-565. doi: 10.1016/j.neuron.2009.04.018

Brown, M., and Ariel, M. (2009). Topography and response timing of intact cerebellum stained with absorbance voltage-sensitive dye. J. Neurophysiol. 101, 474-490. doi: 10.1152/jn.90766.2008

Brown, T. (1911). The intrinsic factors in the act of progression in the mammal. Proc Roy. Soc. Lond. B Biol Sci. 84, 308-319. doi: 10.1098/rspb.1911.0077

Brown, T. (1914). On the nature of the fundamental activity of the nervous centres; together with an analysis of the conditioning of rhythmic activity in progression, and a theory of the evolution of function in the nervous system. J. Physiol. 28, 18-46.

Carpenter, R. (1977). Movements of the Eyes. London: Pion.

Catz, N., Dicke, P. W., and Their, P. (2005) Cerebellar complex spike firing is suitable to induce as well as to stabilize motor learning. Curr. Biol. 15, 2179-2189. doi: 10.1016/j.cub.2005.11.037

Choi, S., Yu, E., Kim, D., Urbano, F. J., Makarenko, V., Shin, H. S., and Llinás, R. R. (2010) Subthreshold membrane potential oscillations in inferior olive neurons are dynamically regulated by $\mathrm{P} / \mathrm{Q}-$ and T-type calcium channels: a study in mutant mice. J. Physiol. 588(Pt 16), 3031-3043. doi: 10.1113/jphysiol.2009.184705

Chomiak, T., S. Peters, and Hu, B. (2008). Functional architecture and spike timing properties of corticofugal projections from rat ventral temporal cortex. J. Neurophysiol. 100, 327-335. doi: 10.1152/jn.90392.2008

Chorev, E., Yarom, Y., and Lampl, I. (2007). Rhythmic episodes of subthreshold membrane potential oscillations in the rat inferior olive nuclei in vivo. J. Neurosci. 27, 5043-5052. doi: 10.1523/JNEUROSCI.5187-06.2007

Condorelli, D. F., Parenti, R., Spinella, F., Trovato Salinaro, A., Belluardo, N., Cardile, V., et al. (1998). Cloning of a new gap junction gene (Cx36) highly expressed in mammalian brain neurons. Eur. J. Neurosci. 10, 1202-1208. doi: 10.1046/j.1460-9568.1998.00163.x

De Gruijl, J. R., Bazzigaluppi, P., de Jeu, M. T., and De Zeeuw, C. I. (2012). Climbing fiber burst size and olivary sub-threshold oscillations in a network setting. PLoS Comput. Biol. 8:e1002814. doi: 10.1371/journal.pcbi.1002814

De Zeeuw, C. I., Chorev, E., Devor, A., Manor, Y., Van Der Giessen, R. S., De Jeu, M. T., et al. (2003). Deformation of network connectivity in the inferior olive of connexin 36-deficient mice is compensated by morphological and electrophysiological changes at the single neuron level. J. Neurosci. 23, 4700-4711.

de Zeeuw, C. I., Holstege, J. C., Ruigrok, T. J., and Voogd, J. (1990a). Mesodiencephalic and cerebellar terminals terminate upon the same dendritic spines in the glomeruli of the cat and rat inferior olive: an ultrastructural study using a combination of $[3 \mathrm{H}]$ leucine and wheat germ agglutinin coupled horseradish peroxidase anterograde tracing. Neuroscience 34, 645-655. doi: 10.1016/03064522(90)90171-y

de Zeeuw, C. I., Ruigrok, T. J., Holstege, J. C., Jansen, H. G., and Voogd, J. (1990b). Intracellular labeling of neurons in the medial accessory olive of the cat: II. Ultrastructure of dendritic spines and their GABAergic innervation. J. Comp. Neurol. 300, 478-494. doi: 10.1002/cne.903000404

de Zeeuw, C. I., Lang, E. J., Sugihara, I., Ruigrok, T. J., Eisenman, L. M., Mugnaini, E., et al. (1996). Morphological correlates of bilateral synchrony in the rat cerebellar cortex. J. Neurosci. 16, 3412-3426.

De Zeeuw, C., Simpson, J., Hoogenraad, C., Galjart, N., Koekkoek, S., and Ruigrok, T. (1998). Microcircuitry and function of the inferior olive. Trends Neurosci. 21, 391-400. doi: 10.1016/S0166-2236(98)01310-1

Devor, A., and Yarom, Y. (2002) Electrotonic coupling in the inferior olivary nucleus revealed by simultaneous double patch recordings. J. Neurophysiol. 87, 3048-3058.

Ebner, T. J., and Chen, G. (1995). Use of voltage-sensitive dyes and optical recordings in the central nervous system. Prog. Neurobiol. 46, 463-506. doi: 10.1016/0301-0082(95)00010-S

Eccles, J. C., Llinás, R., and Sasaki, K. (1965). Inhibitory systems in the cerebellar cortex. Proc. Aust. Assoc. Neurol. 3, 7-14.

Eccles, J. C., Llinás, R., and Sasaki, K. (1966a). The action of antidromic impulses on the cerebellar Purkinje cells. J. Physiol. (Lond.) 182, 316-345.

Eccles, J. C., Llinás, R., and Sasaki, K. (1966b). The excitatory synaptic action of climbing fibres on the purinje cells of the cerebellum. J. Physiol. 182, 268-296.

Eccles, J. C., Llinás, R., and Sasaki, K. (1966c). Intracellularly recorded responses of the cerebellar Purkinje cells. Exp. Brain Res. Exp. Hirnforsch. Exp. Cereb. 1, 161-183. doi: 10.1007/BF00236869

Engel, A. K., Roelfsema, P. R., Fries, P., Brecht, M., and Singer, W. (1997). Role of the temporal domain for response selection and perceptual binding. Cereb. Cortex 7, 571-582. doi: 10.1093/cercor/7.6.571

Farmer, S. F. (1998). Rhythmicity, synchronization and binding in human and primate motor systems. J. Physiol. 509 (Pt 1), 3-14. doi: 10.1111/j.14697793.1998.003bo.x

Fredette, B. J., and Mugnaini, E. (1991). The GABAergic cerebello-olivary projection in the rat. Anat. Embryol. 184, 225-243. doi: 10.1007/BF01673258

Gilbert, P. F., and Thach, W. T. (1977). Purkinje cell activity during motor learning. Brain Res. 128, 309-328. doi: 10.1016/0006-8993(77)90997-0

Hardcastle, V. G. (1997). Consciousness and the neurobiology of perceptual binding. Semin. Neurol. 17, 163-170. doi: 10.1055/s-2008-1040926

Hoge, G. J., Davidson, K. G., Yasumura, T., Castillo, P. E., Rash, J. E., and Pereda, A. E. (2011) The extent and strength of electrical coupling between inferior olivary neurons is heterogeneous. J. Neurophysiol. 105, 1089-1101. doi: 10.1152/jn.00789.2010

Horn, K. M., Pong, M., and Gibson, A. R. (2004). Discharge of inferior olive cells during reaching errors and perturbations.[erratum appears in 
Brain Res. 2004 May 15;1008(1):137-138]. Brain Res. 996, 148-158. doi: 10.1016/j.brainres.2003.10.021

Ito, M., and Yoshida, M. (1966). The origin of cerebral-induced inhibition of Deiters neurones. I. Monosynaptic initiation of the inhibitory postsynaptic potentials. Exp. Brain Res. Exp. Hirnforsch. Exp. Cereb. 2, 330-349.

Jacobson, G. A., Rokni, D., and Yarom, Y. (2008). A model of the olivo-cerebellar system as a temporal pattern generator. Trends Neurosci. 31, 617-625. doi: 10.1016/j.tins.2008.09.005

Jahnsen, H., and Llinás, R. (1984). Ionic basis for the electro-responsiveness and oscillatory properties of guinea-pig thalamic neurones in vitro. J. Physiol. (Lond.) 349, 227-247.

Khosrovani, S., Van Der Giessen, R. S., de Zeeuw, C. I., de Jeu, M. T. (2007). In vivo mouse inferior olive neurons exhibit heterogeneous subthreshold oscillations and spiking patterns. Proc. Natl. Acad. Sci. U.S.A. 104, 15911-15916. doi: 10.1073/pnas.0702727104

Kojima, Y., Soetedjo, R., and Fuchs, A. F. (2010). Changes in simple spike activity of some Purkinje cells in the oculomotor vermis during saccade adaptation are appropriate to participate in motor learning. J. Neurosci. 30, 3715-3727. doi: 10.1523/JNEUROSCI.4953-09.2010

Lampl, I., and Yarom, Y. (1997). Subthreshold oscillations and resonant behavior: two manifestations of the same mechanism. Neuroscience 78, 325-341. doi: 10.1016/S0306-4522(96)00588-X

Lang, E. J. (2001). Organization of olivocerebellar activity in the absence of excitatory glutamatergic input. J. Neurosci. 21, 1663-1675.

Lang, E. J. (2002). GABAergic and glutamatergic modulation of spontaneous and motor-cortex-evoked complex spike activity. J. Neurophysiol. 87, 1993-2008. doi: 10.1152/jn.00477.2001

Lang, E. J., Sugihara, I., and Llinás, R. (1996). GABAergic modulation of complex spike activity by the cerebellar nucleoolivary pathway in rat. J. Neurophysiol. 76, 255-275.

Lang, E. J., Sugihara, I., and Llinás, R. (2006). Olivocerebellar modulation of motor cortex ability to generate vibrissal movements in rat. J. Physiol. 571(Pt 1), 101-120. doi: 10.1113/jphysiol.2005.102764

Leznik, E., and Llinás, R. (2005). Role of gap junctions in synchronized neuronal oscillations in the inferior olive. J. Neurophys. 94, 2447-2456. doi: 10.1152/jn.00353.2005

Leznik, E., Makarenko, V., and Llinás, R. (2002). Electrotonically mediated oscillatory patterns in neuronal ensembles: an in vitro voltage-dependent dye-imaging study in the inferior olive. J. Neurosci. 22, 2804-2815.

Llinás, R. (1974). Eighteenth bowditch lecture: motor aspects of cerebellar control. Physiologist 17, 19-46.

Llinás, R. (1975). Structure and function of the cerebellar cortex. Sci. Am. 232, 56-71.

Llinás, R. (1988). The intrinsic electrophysiological properties of mammalian neurons: a new insight into CNS function. Science 242, 1654-1664.

Llinás, R. (1991). "The noncontinuous nature of movement execution," in Motor Control: Concepts and Issues, eds D. Humphrey and H. Freund (New York, NY: Wiley), 223-242.

Llinás, R. R. (2009). Inferior olive oscillation as the temporal basis for motricity and oscillatory reset as the basis for motor error correction. Neuroscience 162 , 797-804. doi: 10.1016/j.neuroscience.2009.04.045

Llinás, R., Baker, R., and Sotelo, C. (1974). Electrotonic coupling between neurons in cat inferior olive. J. Neurophysiol. 37, 560-571.

Llinás, R., and Hess, R. (1976). Tetrodotoxin-resistant dendritic spikes in avian Purkinje cells. Proc. Natl. Acad. Sci. U.S.A. 73, 2520-2523. doi: 10.1073/pnas. 73.7.2520

Llinás, R., and Jahnsen, H. (1982). Electrophysiology of mammalian thalamic neurones in vitro. Nature 297, 406-408. doi: 10.1038/297406a0

Llinás, R., Leznik, E., and Makarenko, V. I. (2002). On the amazing olivocerebellar system. Ann. N. Y. Acad. Sci. 978, 258-272. doi: 10.1111/j.1749-6632.2002. tb07573.x

Llinás, R., and Muhlethaler, M. (1988). Electrophysiology of guinea-pig cerebellar nuclear cells in the in vitro brain stem-cerebellar preparation. J. Physiol. 404, 241-258.

Llinás, R., and Sugimori, M. (1980a). Electrophysiological properties of in vitro Purkinje cell somata in mammalian cerebellar slices. J. Physiol. 305, 171-195.

Llinás, R., and Sugimori, M. (1980b). Electrophysiological properties of in vitro Purkinje cell dendrites in mammalian cerebellar slices. J. Physiol. 305, 197-213.
Llinás, R., and Yarom, Y. (1981a). Electrophysiology of mammalian inferior olivary neurones in vitro. Different types of voltage-dependent ionic conductances. J. Physiol. 315, 549-567.

Llinás, R., and Yarom, Y. (1981b). Properties and distribution of ionic conductances generating electroresponsiveness of mammalian inferior olivary neurones in vitro. J. Physiol. 315, 569-584.

Llinás, R., and Yarom, Y. (1986). Oscillatory properties of guinea-pig inferior olivary neurones and their pharmacological modulation: an in vitro study. J. Physiol. 376, 163-182.

Llinás, R., Ribary, U., Contreras, D., and Pedroarena, C. (1998). The neuronal basis for consciousness. Philos. Trans. R. Soc. Lond. B Biol. Sci. 353, 1841-1849. doi: 10.1098/rstb.1998.0336

Long, M. A., Deans, M. R., Paul, D. L., and Connors, B. W. (2002). Rhythmicity without synchrony in the electrically uncoupled inferior olive. J. Neurosci. 22, 10898-10905.

Makarenko, V., and Llinás, R. (1998). Experimentally determined chaotic phase synchronization in a neuronal system. Proc. Natl. Acad. Sci. U.S.A. 95, 15747-15752. doi: 10.1073/pnas.95.26.15747

Manor, Y., Rinzel, J., Segev, I., and Yarom, Y. (1997). Low-amplitude oscillations in the inferior olive: a model based on electrical coupling of neurons with heterogeneous channel densities. J. Neurophysiol. 77, 2736-2752.

Manor, Y., Yarom, Y., Chorev, E., and Devor, A. (2000). To beat or not to beat: a decision taken at the network level. J. Physiol. Paris 94, 375-390. doi: 10.1016/S0928-4257(00)01085-8

Marder, E., and Bucher, D. (2001). Central pattern generators and the control of rhythmic movements. Curr. Biol. 11, R986-R996. doi: 10.1016/S09609822(01)00581-4

Mathy, A., Ho, S. S., Davie, J. T., Duguid, I. C., Clark, B. A., and Hausser, M. (2009) Encoding of oscillations by axonal bursts in inferior olive neurons. Neuron 62, 388-399. doi: 10.1016/j.neuron.2009.03.023

Medina, J. F., Nores, W. L., and Mauk, M. D. (2002). Inhibition of climbing fibres is a signal for the extinction of conditioned eyelid responses. Nature 416, 330-333 doi: $10.1038 / 416330$ a

Pare, D., deCurtis, M., and Llinás, R. (1992). Role of the hippocampal-entorhinal loop in temporal lobe epilepsy: extra- and intracellular study in the isolated guinea pig brain in vitro. J. Neurosci. 12, 1867-1881.

Popa, L. S., Hewitt, A. L., and Ebner, T. J. (2012). Predictive and feedback performance errors are signaled in the simple spike discharge of individual Purkinje cells. J. Neurosci. 32, 15345-15358. doi: 10.1523/JNEUROSCI.2151-12.2012

Popa, L. S., Hewitt, A. L., and Ebner, T. J. (2013). Purkinje cell simple spike discharge encodes error signals consistent with a forward internal model. Cerebellum 12, 331-333. doi: 10.1007/s12311-013-0452-4

Ramon y Cajal, S. (1911). Histologie du Systeme Nerveux de l'homme et des Vertebres, Vol. II. Paris: Maloine.

Rash, J. E., Yasumura, T., Dudek, F. E., and Nagy, J. I. (2001). Cell specific expression of connexins and evidence of restricted gap junctional coupling between glial cells and between neurons. J. Neurosci. 21, 1983-2000.

Ruigrok, T. J., and Voogd, J. (1995). Cerebellar influence on olivary excitability in the cat. Eur. J. Neurosci. 7, 679-693. doi: 10.1111/j.1460-9568.1995.tb00672.x

Salami, M., Itami, C., Tsumoto, T., and Kimura, F. (2003). Change of conduction velocity by regional myelination yields constant latency irrespective of distance between thalamus and cortex. Proc. Natl. Acad. Sci. U.S.A. 100, 6174-6179. doi: 10.1073/pnas.0937380100

Schweighofer, N., Doya, K., and Kawato, M. (1999). Electrophysiological properties of inferior olive neurons: a compartmental model. J. Neurophysiol. 82, 804-817.

Schweighofer, N., Doya, K., Fukai, H., Chiron, J. V., Furukawa, T., and Kawato, M. (2004a). Chaos may enhance information transmission in the inferior olive. Proc. Natl. Acad. Sci. U.S.A. 101, 4655-4660. doi: 10.1073/pnas.0305966101

Schweighofer, N., Doya, K., and Kuroda, S. (2004b). Cerebellar aminergic neuromodulation: towards a functional understanding. Brain Res. Brain Res. Rev. 44, 103-116. doi: 10.1016/j.brainresrev.2003.10.004

Sherrington, C. (1906). The Integrative Actions of the Nervous System. New Haven, CT: Yale University Press.

Simpson, J. I., Wylie, D. R., and De Zeeuw, C. I. (1996). More on climbing fiber signals and their consequence(s). Behav. Brain Sci. 384-398. doi: 10.1017/S014 0525X00081991

Singer, W. (1993). Synchronization of cortical activity and its putative role in information processing and learning. Annu. Rev. Physiol. 55, 349-374. doi: 10.1146/annurev.ph.55.030193.002025 
Sotelo, C., Gotow, T., and Wassef, M. (1986). Localization of glutamic-aciddecarboxylase-immunoreactive axon terminals in the inferior olive of the rat, with special emphasis on anatomical relations between GABAergic synapses and dendrodendritic gap junctions. J. Comp. Neurol. 252, 32-50. doi: $10.1002 /$ cne. 902520103

Sotelo, C., Llinás, R., and Baker, R. (1974). Structural study of inferior olivary nucleus of the cat: morphological correlates of electrotonic coupling. J. Neurophysiol. 37, 541-559.

Sugihara, I., Lang, E. J., and Llinás, R. (1993). Uniform olivocerebellar conduction time underlies Purkinje cell complex spike synchronicity in the rat cerebellum. J. Physiol. 470, 243-271. doi: 10.1016/S0921-8696(05)81125-9

Szentagothai, J., and Rajkovits, K. (1959). Ueber den Ursprung der Kletterfasern des kleinhirns. Z. Anat. Entwicklungsgeschicht. 121, 130-141. doi: 10.1007/BF00525203

Thach, W. (1968). Discharge of Purkinje and cerebellar nuclear neurons during rapidly alternating arm movements in the monkey. J. Neurophysiol. 31, 785-797.

Torben-Nielsen, B., Segev, I., and Yarom, Y. (2012) The generation of phase differences and frequency changes in a network model of inferior olive subthreshold oscillations. PLoS Comput. Biol. 8:e1002580. doi: 10.1371/journal.pcbi. 1002580

Urbano, F. J., Simpson, J. I., and Llinás, R. R. (2006). Somatomotor and oculomotor inferior olivary neurons have distinct electrophysiological phenotypes. Proc. Natl. Acad. Sci. U.S.A. 103, 16550-16555. doi: 10.1073/pnas.0607888103

Vallbo, A. B., and Wessberg, J. (1993). Organization of motor output in slow finger movements in man. J. Physiol. 469, 673-691.

Van Der Giessen, R. S., Koekkoek, S. K., van Dorp, S., De Gruijl, J. R., Cupido, A., Khosrovani, S., et al. (2008). Role of olivary electrical coupling in cerebellar motor learning. Neuron 58, 599-612. doi: 10.1016/j.neuron.2008.03.016

Varela, F., Lachaux, J. P., Rodriguez, E., and Martinerie, J. (2001). The brainweb: phase synchronization and large-scale integration. Nat. Rev. Neurosci. 2, 229-239. doi: 10.1038/35067550

Velarde, M. G., Nekorkin, V. I., Kazantsev, V. B., Makarenko, V. I., and Llinás, R. (2002). Modeling inferior olive neuron dynamics. Neural Net. 15, 5-10. doi: 10.1016/S0893-6080(01)00130-7
Vicente, R., Gollo, L. L., Mirasso, C. R., Fischer, I., and Pipa, G. (2008). Dynamical relaying can yield zero time lag neuronal synchrony despite long conduction delays. Proc. Natl. Acad. Sci. U.S.A. 105, 17157-17162. doi: 10.1073/pnas.0809353105

Welsh, J. P., and Llinás, R. (1997). Some organizing principles for the control of movement based on olivocerebellar physiology. Prog. Brain Res. 114, 449-461. doi: 10.1016/S0079-6123(08)63380-4

Welsh, J. P., Lang, E. J., Sugihara, I., and Llinás, R. (1995). Dynamic organization of motor control within the olivocerebellar system. Nature 374, 453-457. doi: 10.1038/374453a0

Yarom, Y., and Cohen, D. (2002). The olivocerebellar system as a generator of temporal patterns. Ann. N.Y. Acad. Sci. 978, 122-134. doi: 10.1111/j.17496632.2002.tb07561.x

Conflict of Interest Statement: The author declares that the research was conducted in the absence of any commercial or financial relationships that could be construed as a potential conflict of interest.

Received: 10 January 2013; accepted: 25 October 2013; published online: 28 January 2014.

Citation: Llinás RR (2014) The olivo-cerebellar system: a key to understanding the functional significance of intrinsic oscillatory brain properties. Front. Neural Circuits 7:96. doi: 10.3389/fncir.2013.00096

This article was submitted to the journal Frontiers in Neural Circuits.

Copyright (c) 2014 Llinás. This is an open-access article distributed under the terms of the Creative Commons Attribution License (CCBY). The use, distribution or reproduction in other forums is permitted, provided the original author(s) or licensor are credited and that the original publication in this journal is cited, in accordance with accepted academic practice. No use, distribution or reproduction is permitted which does not comply with these terms. 